\title{
PHARMACOLOGICAL TREATMENT OF GESTATIONAL DIABETES
}

\section{Carneiro ${ }^{1}$, S. Bernardes da Cunha ${ }^{1}$, V. Ferreira ${ }^{1}$, C. Rasteiro ${ }^{1,2}$, C. Araujo $^{1}$, T. Teles $^{1}$}

1. Centro Hospitalar entre o Douro e Vouga, EPE, Santa Maria da Feira.

2. Faculdade de Ciências da Saúde, Universidade da Beira Interior, Covilhã.

\section{Problem statement}

Gestational Diabetes (GD) is associated with several maternal/fetal complications and its adequate metabolic control may allow to minimize them. Currently, the two most oftenly used pharmacological agents are: metformin and insulin. The latter is considered first line because of its safety and efficiency. However, metformin, for its convenience, lower price and better performance in pregnancy weight gain control is a frequently used alternative. ${ }^{1,2}$

Some studies associated metformin with a slight increase in the risk of prematurity and lower birth weight. ${ }^{3}$

The aim of this study was to evaluate maternal and neonatal outcomes according to the pharmacological therapy used (metformin versus insulin). ${ }^{2}$

\section{Methods}

Retrospetive analysis of singleton pregnancies with GD with delivery in our hospital.

Period of study: 04/2015 - 07/2019.

Cases without pharmacological treatment were excluded.

Maternal characteristics, pregnancy outcomes and neonatal outcomes were assessed.

2 dichotomic variables were created:

Maternal outcomes: preterm delivery, hypertensive complications, $3^{\text {rd }}$ degree laceration, cesarean section;

Neonatal outcomes: macrosomia, large for gestational age (LGA); small for gestational age (SGA); apgar index (Al) <7 at $5^{\prime}$ minute, need for oxygen therapy or intubation, admission to the neonatal intensive care unit (UCIN).

\section{Results}

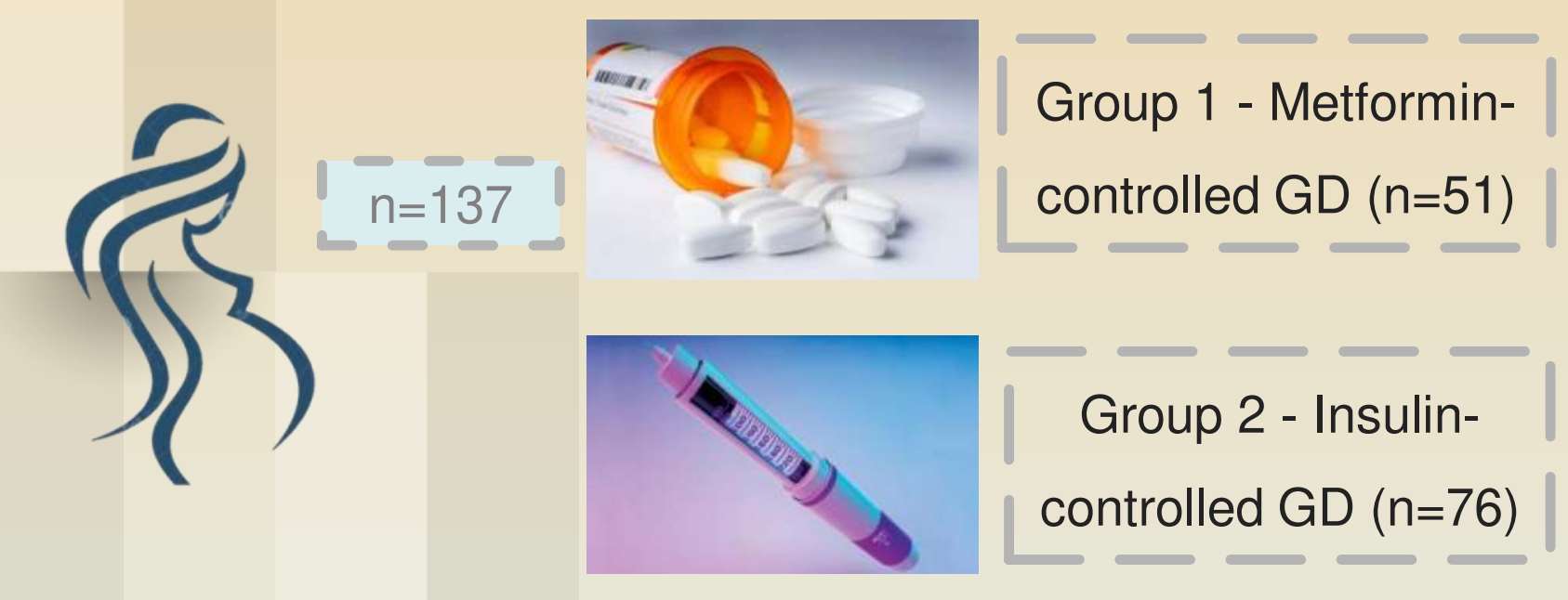

No differences were found in maternal characteristics between the two groups.

\begin{tabular}{c|c|c|c|}
\hline Outcome & Group 1 & Group 2 & p value \\
\hline $\begin{array}{c}\text { Maternal age } \\
\text { (mean, years) }\end{array}$ & 34,76 & 34,62 & $\mathrm{p}=0.87$ \\
$\begin{array}{c}\text { Gestational } \\
\text { age } \\
\text { (mean, weeks) }\end{array}$ & 38,8 & 38,2 & $\mathrm{p}=0.03$ \\
\hline $\begin{array}{c}\text { Composed } \\
\text { maternal }\end{array}$ & $20(76,9 \%)$ & $39(84,8 \%)$ & $\mathrm{p}=0.53$ \\
$\begin{array}{c}\text { outcomes (n,\%) } \\
\text { Macrosomia } \\
\text { (n,\%) }\end{array}$ & $1(2,0 \%)$ & $3(3,9 \%)$ & $\mathrm{p}=0.65$ \\
\hline $\begin{array}{c}\text { Admission to } \\
\text { UCIN (n,\%) }\end{array}$ & $1(2,0 \%)$ & $5(6,6 \%)$ & $\mathrm{p}=0.40$ \\
\hline
\end{tabular}

No differences were found in hypertensive complications of pregnancy, type of delivery, labor induction rate, urgent/emergent cesarean section, birth trauma, birth weight, rate of macrosomia or LGA or composed maternal outcomes between groups.

Prematurity rate was higher in group 2 ( 0 vs $11,8 \%, p=0.011)$.

When considering a composed neonatal outcome, group 2 had worse outcomes $(34,2 \%$ vs. $15,7 \% p=0.025)$, with no differences reported in a composed maternal outcome.

\section{Conclusions}

In our study, individual maternal and neonatal outcomes were similar between the two groups.

However, considering the composed adverse neonatal outcomes, pregnant women with GD treated with insulin had worse outcomes.

In this way, our results, although using a small sample, don't allow to confirm previous studies.

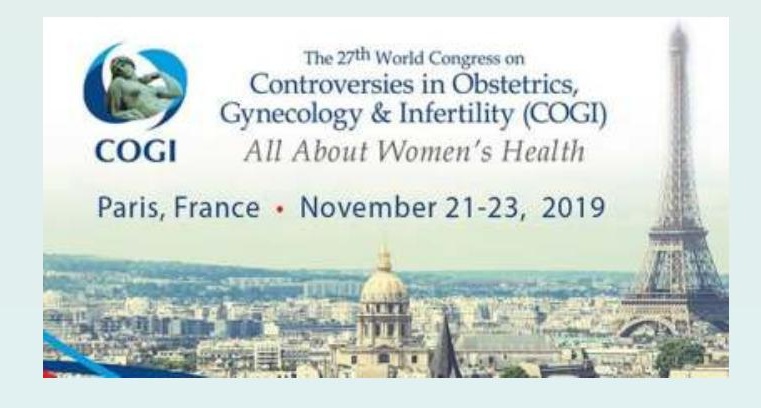

